\title{
Occupational risk factors for ill health in Gulf veterans of the United Kingdom
}

Khalida Ismail, Nick Blatchley, Matthew Hotopf, Lisa Hull, Ian Palmer, Catherine Unwin, Anthony David, Simon Wessely

\begin{abstract}
Objectives-To study the association between occupational factors specific to the Armed Forces (rank, functional roles, Service, regular or reservist status and deployment factors) and symptomatic health problems in Gulf veterans, after sociodemographic and lifestyle factors have been accounted for.
\end{abstract}

Design-A postal cross sectional survey of randomly selected UK Gulf veterans was conducted six to seven years after the Gulf conflict. Physical ill health was measured using the Fatigue Questionnaire and a measure of the Centers for Disease Control and Prevention (CDC) multisymptom syndrome. Psychological ill health was measured using the General Health Questionnaire and a posttraumatic stress measure.

Setting-Population of servicemen who were serving in the UK Armed Forces during the Gulf conflict between 1 September 1990 and 30 June 1991.

Participants-3297 Gulf veterans.

Main results-In multivariate logistic regression, there was an inverse relation between higher rank and psychological and physical ill health (test of trend: General Health Questionnaire, $p=0.004$; posttraumatic stress, $p=0.002$; fatigue, $p=0.015$; CDC case, $p=0.002$ ). Having left the Armed Forces was associated with a two to three times increase in reporting ill health. Of the deployment factors, there was a weak association between being deployed as an individual reinforcement in a combat role and post-traumatic stress but there was no association between receiving pre-deployment training or post-deployment leave and ill health. Marital status and smoking were associated with psychological and physical ill health.

Conclusions-Rank was the main occupational factor associated with both psychological and physical ill health in Gulf veterans. This may parallel the associations between socioeconomic status and morbidity in civilian populations. Ill health seems to be greater in those who return to civilian life. Sociodemographic factors also seem to be important in ill health in Gulf veterans.

(F Epidemiol Community Health 2000;54:834-838)

Correspondence to: Dr Ismail

(khalida.ismail@iop.kcl.ac.uk)

Accepted for publication 20 May 2000 report more health problems than military personnel not deployed to the Gulf. ${ }^{1-3}$ The nature of these health problems are still not clear, but symptoms include fatigue, headaches, poor concentration and joint pains. ${ }^{1-3}$ Aetiological evidence for specific exposures in the Gulf such as suspected chemical weapons, organophosphate pesticides, immunisations, pyridostigmine bromide, oil well fires and depleted uranium has been inconsistent, ${ }^{4}$ probably reflecting serious measurement biases.

Little attention has been given to occupational factors specific to military populations, such as trade, Service, rank and reserve duty that may be proxy markers for ill health in Gulf veterans. In the United Kingdom, Army personnel are grouped into three main functional roles, within which a variety of trades are performed; Combat Arm, such as the Infantry and the Royal Armoured Corps, where personnel are more likely to be involved in combat; Combat Support Arm, such as the Royal Engineers; and Combat Services Support Arm, such as the Royal Army Medical Corps. Roles in the Royal Navy or Royal Air Force are not directly comparable as entire ships and airfields are at risk of attack. Army personnel may have been in closer geographical proximity to some of the environmental exposures implicated in Gulf related ill health than the Royal Navy or Royal Air Force, such as pesticides and oil well fires, although there is no published evidence for this and the Royal Air Force also had extensive ground bases. It is also possible that servicemen from lower ranks had different experiences to those of higher ranks who often have greater organisational responsibilities. Reserve duty has been suggested as significant. $^{256}$

Since the first world war, preparing personnel for conflict is integral to military training. Personnel are encouraged to identify with their Units and are trained in helping their colleagues to normalise acute stress reactions. ${ }^{7}$ There is much speculation that being deployed as an individual reinforcement to a different unit, not receiving pre-deployment training and lack of post-deployment leave may be associated with symptomatic distress in Gulf veterans. These factors are potential targets for intervention but have not been systematically studied.

Little attempt has been made to apply risk factors for ill health in civilian populations to military populations. Sociodemographic risk patterns of illnesses, such as age, education, socioeconomic status, marital status and lifestyle factors such as smoking and alcohol 
intake, may have an independent role in ill health in Gulf veterans. One study reported that older, divorced and enlisted US Gulf veterans were more likely to report physical symptoms. ${ }^{1}$ It is not straightforward to use a serviceman's trade to classify his socioeconomic status because within a trade there is a hierarchy of rank and certain trades are unique to the military.

The main aim of this study is to examine whether certain military and deployment factors are associated with increased reporting of ill health in Gulf veterans, taking into account potential sociodemographic confounders.

\section{Methods}

DESIGN, POPULATION AND SAMPLE

A cross sectional postal survey was conducted on a randomly selected sample of UK Armed Forces servicemen who were deployed to the Gulf between 1 September 1990 and 30 June 1991 ( $n=3905)$. Further details of sampling methods, tracing and response rates have been previously described.

\section{MEASUREMENT OF RISK FACTORS \\ Specific military factors}

We asked which Service of the Armed ForcesRoyal Navy including Royal Marines, Army or the Royal Air Force - the participant was in at the time of deployment. Rank was classified

Table 1 Number of individualst (\% cases) in each category and multivariate odds ratios (95\% confidence intervals) using logistic regression for fatigue and CDC syndrome in Gulf male veterans

\begin{tabular}{|c|c|c|c|c|}
\hline \multirow[b]{2}{*}{ Explanatory variable } & \multicolumn{2}{|l|}{ Fatigue } & \multicolumn{2}{|c|}{ CDC syndrome } \\
\hline & $\begin{array}{l}\text { Number of } \\
\text { individuals } \\
\text { (\% cases) }\end{array}$ & $\begin{array}{l}\text { Adjusted* } \\
\text { odds ratio }\end{array}$ & $\begin{array}{l}\text { Number of } \\
\text { individuals } \\
\text { (\% cases) }\end{array}$ & $\begin{array}{l}\text { Adjusted* } \\
\text { odds ratio }\end{array}$ \\
\hline \multicolumn{5}{|l|}{ Age group (y) } \\
\hline$<20$ & $292(51.4)$ & 1 & $302(17.6)$ & 1 \\
\hline $20-29$ & $1883(46.6)$ & $1.0(0.7,1.3)$ & $1924(16.4)$ & $1.2(0.8,1.7)$ \\
\hline $30-39$ & $809(47.0)$ & $1.0(0.7,1.4)$ & $833(18.1)$ & $1.4(0.8,2.2)$ \\
\hline$\geqslant 40$ & $179(43.0)$ & $1.1(0.6,2.1)$ & $191(18.3)$ & $2.8(1.3,5.9)$ \\
\hline \multicolumn{5}{|l|}{ Education } \\
\hline$<\mathrm{O}$ levels/GCSEs & $598(56.9)$ & 1 & $621(22.4)$ & 1 \\
\hline O levels/GCSEs & $1863(46.4)$ & $0.7(0.6,0.9)$ & $1911(16.6)$ & $0.8(0.6,1.0)$ \\
\hline A levels and > & $603(35.5)$ & $0.8(0.8,1.4)$ & $617(10.7)$ & $0.8(0.5,1.3)$ \\
\hline Married & $2397(45.6)$ & 1 & $2454(16.0)$ & 1 \\
\hline Single & $476(46.9)$ & $1.1(0.8,1.4)$ & $493(17.2)$ & $1.1(0.8,1.5)$ \\
\hline $\begin{array}{l}\text { Ex married } \\
\text { Alcohol intake }\end{array}$ & \multicolumn{4}{|c|}{ Alcohol intake } \\
\hline None & $243(54.3)$ & 1 & $253(25.7)$ & 1 \\
\hline$<21$ units & $2485(46.8)$ & $0.7(0.5,1.0)$ & $2541(16.3)$ & $0.6(0.4,0.9)$ \\
\hline$>21$ units & $420(43.6)$ & $0.6(0.4,0.9)$ & $439(16.4)$ & $0.6(0.6,1.0)$ \\
\hline \multicolumn{5}{|l|}{ Smoking } \\
\hline Current & $1161(55.6)$ & 1 & $1192(23.9)$ & 1 \\
\hline Ex smoker & $762(44.5)$ & $0.8(0.7,1.0)$ & $783(15.7)$ & $0.8(0.6,1.0)$ \\
\hline Non-smoker & $1221(40.0)$ & $0.7(0.6,0.8)$ & $1255(11.6)$ & $0.6(0.4,0.7)$ \\
\hline \multicolumn{5}{|l|}{ Service } \\
\hline Army & $2397(50.2)$ & 1 & $2470(19.4)$ & 1 \\
\hline Royal Navy & $271(38.9)$ & $0.9(0.2,3.1)$ & $276(9.8)$ & $\ddagger$ \\
\hline Royal Air Force & $447(36.2)$ & $2.1(0.6,7.3)$ & $453(10.6)$ & $1.2(0.3,5.9)$ \\
\hline \multicolumn{5}{|l|}{ Regular status } \\
\hline Regular & $2966(47.4)$ & 1 & $3044(17.3)$ & 1 \\
\hline Reservist & $48(45.8)$ & $1.0(0.4,2.2)$ & $49(20.4)$ & $0.7(0.2,2.3)$ \\
\hline \multicolumn{5}{|l|}{ Rank } \\
\hline Private & $1180(50.8)$ & 1 & $1215(19.7)$ & 1 \\
\hline Non-commissioned officer & $1577(48.7)$ & $0.9(0.7,1.1)$ & $1617(17.8)$ & $0.8(0.6,1.0)$ \\
\hline Officer & $328(29.0)$ & $0.5(0.3,0.8)$ & $337(6.5)$ & $0.3(0.1,0.6)$ \\
\hline \multicolumn{5}{|l|}{ Combat arm } \\
\hline Combat Services Support & $991(50.6)$ & 1 & $1017(20.4)$ & 1 \\
\hline Combat Support & $1066(49.3)$ & $0.9(0.8,1.1)$ & $1094(18.3)$ & $1.0(0.8,1.2)$ \\
\hline Combat & $144(60.4)$ & $1.5(1.0,2.2)$ & $150(22.7)$ & $1.2(0.8,1.9)$ \\
\hline
\end{tabular}

*Adjusted for all other variables in table. $\dagger$ Denominators for each outcome differ slightly because of missing values on some items. $\ddagger$ Empty cell. into three categories; privates (and their equivalents); non-commissioned officers (NCOs); and officers. NCOs are usually personnel who have moved up the ranks through merit, whereas officers are commissioned into the military, usually with a higher level of education and officer training before joining. We categorised the serviceman's main role during deployment as within a Combat Services Support Arm, Combat Support Arm or Combat Arm, according to accepted military classification of combat status of Corps. We asked whether he was a reservist or regular at the time of deployment, and whether he was currently serving.

\section{Deployment factors}

Team support was labelled "Unit status" and measured by asking the respondent whether he had been deployed with his Unit, part of his Unit or as an individual reinforcement to a different Unit. We also asked whether he had received pre-deployment training and whether he had post-deployment leave.

\section{Sociodemographic factors}

We measured age on 1 January 1991, marital status, alcohol consumption per week and smoking when completing questionnaire and pre-military educational attainment.

\section{MEASUREMENT OF OUTCOMES}

As there is no consensus on the definition of Gulf related ill health we used two physical health status measures, fatigue and physical symptoms and two mental health status measures, psychological distress and post-traumatic stress. We defined a fatigue case as a score of 4 or above using the Chalder Fatigue questionnaire. ${ }^{8}$ We derived a measure of the Centers for Disease Control and Prevention (CDC) case definition of multisymptoms in Gulf War veterans ${ }^{1}$ using a standardised 50 item symptom questionnaire as previously described. ${ }^{39}$ We defined psychological distress as a score of $>2$ on the General Health Questionnaire-12. ${ }^{10}$ We labelled a proxy measure of post-traumatic stress as "post-traumatic stress reaction" based on symptoms in our questionnaire that matched the three symptom groups for diagnosis of post-traumatic stress disorder, intrusive thoughts, avoidance and arousal, respectively. ${ }^{311}$

\section{STATISTICAL ANALYSES}

SPSS 8.1 and STATA 5 statistical packages were used to store and analyse the data, respectively. Multivariate analysis, using logistic regression, was used to adjust the association between military, sociodemographic and lifestyle variables and each health outcome, and reported as odds ratios and 95\% confidence intervals. Test for trend was performed for ordered categorical variables (age, education, smoking, alcohol intake, rank and combat arm) using the likelihood ratio test statistic. We examined the univariate and multivariate associations between Unit status (Army only), predeployment training and post-deployment leave with military, sociodemographic and 
Table 2 Number of individualst (\% cases) in each category and multivariate odds ratios (95\% confidence intervals) using logistic regression for psychological distress and posttraumatic stress reaction in Gulf male veterans

\begin{tabular}{|c|c|c|c|c|}
\hline \multirow[b]{2}{*}{ Explanatroy variable } & \multicolumn{2}{|c|}{ Psychological distress } & \multicolumn{2}{|c|}{ Post-traumatic stress reaction } \\
\hline & $\begin{array}{l}\text { Number of } \\
\text { individuals } \\
\text { (\% cases) }\end{array}$ & $\begin{array}{l}\text { Adjusted } \\
\text { odds ratio }\end{array}$ & $\begin{array}{l}\text { Number of } \\
\text { individuals } \\
\text { (\% cases) }\end{array}$ & $\begin{array}{l}\text { Adjusted } \\
\text { odds ratio }\end{array}$ \\
\hline \multicolumn{5}{|l|}{ Age group (y) } \\
\hline$<20$ & $296(37.8)$ & 1 & $303(17.5)$ & 1 \\
\hline $20-29$ & $1888(39.7)$ & $1.3(0.9,1.7)$ & $1937(13.4)$ & $1.0(0.7,1.5)$ \\
\hline $30-39$ & $821(39.0)$ & $1.3(0.9,1.8)$ & $849(12.1)$ & $1.0(0.6,1.7)$ \\
\hline$\geqslant 40$ & $188(38.3)$ & $1.8(1.0,3.2)$ & $194(8.8)$ & $0.9(0.4,2.3)$ \\
\hline \multicolumn{5}{|l|}{ Education } \\
\hline$<$ O levels/GCSEs & $609(43.3)$ & 1 & $630(17.5)$ & 1 \\
\hline O levels/GCSEs & $1884(39.2)$ & $0.9(0.7,1.1)$ & $1926(12.8)$ & $0.7(0.5,0.9)$ \\
\hline \multicolumn{5}{|l|}{ Marital status } \\
\hline Married & $2407(36.8)$ & 1 & $2478(11.5)$ & 1 \\
\hline Single & $487(40.7)$ & $1.2(0.9,1.5)$ & $496(16.5)$ & $1.4(1.0,2.0)$ \\
\hline Ex married & $283(56.2)$ & $2.2(1.6,3.0)$ & $292(21.6)$ & $2.0(1.4,2.9)$ \\
\hline \multicolumn{5}{|l|}{ Alcohol intake } \\
\hline None & $248(43.5)$ & 1 & $256(15.2)$ & 1 \\
\hline$<21$ units & $2501(38.8)$ & $0.9(0.6,1.2)$ & $2564(12.4)$ & $1.1(0.7,1.8)$ \\
\hline$>21$ units & $428(38.8)$ & $0.8(0.5,1.2)$ & $446(16.1)$ & $1.3(0.8,2.3)$ \\
\hline \multicolumn{5}{|l|}{ Smoking } \\
\hline Current & $1167(46.6)$ & 1 & $1206(19.3)$ & 1 \\
\hline Ex smoker & $773(36.1)$ & $0.8(0.7,1.0)$ & $788(11.2)$ & $0.6(0.5,0.9)$ \\
\hline Non-smoker & $1234(33.8)$ & $0.7(0.6,0.9)$ & $1268(8.6)$ & $0.5(0.4,0.7)$ \\
\hline \multicolumn{5}{|l|}{ Service } \\
\hline Army & $2424(41.9)$ & 1 & $2473(15.7)$ & 1 \\
\hline Royal Navy & $276(31.5)$ & $0.3(0.1,1.6)$ & $276(5.8)$ & $\ddagger$ \\
\hline Royal Air Force & $444(10.8)$ & $0.7(0.2,2.5)$ & $455(6.1)$ & $0.8(0.1,6.6)$ \\
\hline \multicolumn{5}{|l|}{ Regular status } \\
\hline Regular & $2992(39.5)$ & 1 & 3049 (13.4) & 1 \\
\hline Reservist & $48(37.8)$ & $0.7(0.3,1.7)$ & $50(17.0)$ & $2.0(0.7,5.4)$ \\
\hline \multicolumn{5}{|l|}{ Rank } \\
\hline Private & $1189(42.3)$ & 1 & $1218(16.1)$ & 1 \\
\hline Non-commissioned officer & $1596(40.2)$ & $0.8(0.6,0.9)$ & $1620(13.3)$ & $0.9(0.6,1.1)$ \\
\hline Officer & 330 & $0.5(0.3,0.8)$ & $337(5.0)$ & $0.3(0.2,0.7)$ \\
\hline \multicolumn{5}{|l|}{ Combat arm } \\
\hline Combat Services Support & $999(44.4)$ & 1 & $1019(16.8)$ & 1 \\
\hline Combat Support & $1076(40.1)$ & $0.9(0.7,1.0)$ & $1096(13.9)$ & $0.8(0.6,1.0)$ \\
\hline Combat & $150(41.3)$ & $1.0(0.7,1.4)$ & $150(16.7)$ & $0.9(0.5,1.6)$ \\
\hline
\end{tabular}

^Adjusted for all other variables in table. †Denominators for each outcome differ slightly because of missing values on some items. $\ddagger$ Empty cell.

lifestyle variables. We also used the likelihood ratio test statistic to examine whether the effect of Combat Arm on each of the health outcomes was modified by Unit status and/or rank in Army servicemen. Cases with missing data were excluded.

\section{Results}

Three mailings were conducted from August 1997 to June 1998 . The response rate was $70 \%$ $(n=2735)$. In addition, a small proportion of respondents from a Bosnia comparison sample $(n=562)$ who had also served in the Gulf were taken to be part of Gulf cohort. ${ }^{3}$ Responders were slightly older and more likely to be still in service; details of this have been published. ${ }^{3}$
The distribution of, and adjusted odds ratios for fatigue and CDC syndrome cases in each military, sociodemographic and lifestyle category, is shown in table 1 . These analyses are repeated for psychological distress and posttraumatic stress reaction in table 2. There was no association between the Service, Combat Arm or reservist status and any of the four health outcomes. There was a significant inverse relation between increasing rank and all health outcomes; fatigue ( $\mathrm{p}=0.015), \mathrm{CDC}$ syndrome $(p=0.002)$, psychological distress $(\mathrm{p}=0.004)$ and post-traumatic stress reaction $(\mathrm{p}=0.002)$.

There was no association between increasing age and any of the four health outcomes, except that servicemen $\geqslant 40$ years old were significantly more likely to have psychological distress and CDC syndrome compared with servicemen $<20$ years old. There was a small significant trend between educational attainment before joining the Armed Forces and fatigue $(p=0.036)$.

Divorced, separated or widowed status was significantly associated with CDC syndrome, psychological distress and post-traumatic stress reaction but not with fatigue.

There was a linear trend between smoking and all health outcomes; fatigue $(\mathrm{p}<0.00001)$, CDC syndrome $(\mathrm{p}<0.00001)$ and psychological distress $(p<0.00001)$ and post-traumatic stress reaction $(p<0.0001)$, but none with alcohol consumption.

At time of the survey, 57\% $(n=1967)$ of Gulf veterans had left the Armed Forces. After adjusting for the potential confounders listed in table 1, those who had left were more likely to have fatigue (odds ratio $=1.4,95 \%$ confidence intervals $(95 \% \mathrm{CI}) 1.2,1.7)$, CDC syndrome (odds ratio $=1.8,95 \%$ CI 1.5, 2.3), psychological distress (odds ratio $=1.6,95 \%$ CI $1.3,1.9$ ), and post-traumatic stress reaction (odds ratio $=2.5,95 \%$ CI $1.9,3.2)$.

Forty nine per cent $(n=1236)$ of Army servicemen were deployed with their Unit, 35\% $(n=855)$ were deployed with part of their Unit and $15 \% \quad(n=358)$ were deployed as an individual reinforcement. In both univariate and multivariate analysis, there was no association between Unit status and any health outcome (table 3).

Eighty three per cent $(n=2660)$ of Gulf veterans undertook pre-deployment training. Predeployment training was associated with an

Table 3 Unadjusted and adjusted $\dagger$ odds ratios using logistic regression of the association between deployment factors and all four health outcomes

\begin{tabular}{|c|c|c|c|c|c|c|c|c|}
\hline & \multicolumn{2}{|l|}{ Fatigue } & \multicolumn{2}{|l|}{ CDC syndrome } & \multicolumn{2}{|c|}{ Psychological distress } & \multicolumn{2}{|c|}{ Post-traumatic stress reaction } \\
\hline & Odds ratio & $\begin{array}{l}\text { Adjusted } \\
\text { odds ratio }\end{array}$ & Odds ratio & $\begin{array}{l}\text { Adjusted } \\
\text { odds ratio }\end{array}$ & Odds ratio & $\begin{array}{l}\text { Adjusted } \\
\text { odds ratio }\end{array}$ & Odds ratio & $\begin{array}{l}\text { Adjusted } \\
\text { odds ratio }\end{array}$ \\
\hline \multicolumn{9}{|l|}{ Unit status $^{*}$} \\
\hline Deployed with whole Unit & 1 & 1 & 1 & 1 & 1 & 1 & 1 & 1 \\
\hline Deployed with part of Unit & $1.0(0.9,1.1)$ & $0.9(0.8,1.1)$ & $1.1(0.9,1.3)$ & $1.0(0.8,1.3)$ & $1.1(0.9,1.3)$ & $1.0(0.9,1.3)$ & $1.1(0.9,1.4)$ & $1.1(0.8,1.4)$ \\
\hline $\begin{array}{l}\text { Deployed as an individual } \\
\text { reinforcement }\end{array}$ & $0.8(0.7,1.1)$ & $1.0(0.8,1.3)$ & $1.0(0.7,1.3)$ & $1.1(0.8,1.6)$ & $1.0(0.8,1.2)$ & $1.1(0.8,1.4)$ & $0.8(0.6,1.2)$ & $0.9(0.6,1.3)$ \\
\hline \multicolumn{9}{|l|}{ Predeployment training } \\
\hline Yes & 1 & 1 & 1 & 1 & 1 & 1 & 1 & 1 \\
\hline No & $0.8(0.6,0.9)$ & $1.1(0.8,1.4)$ & $0.8(0.6,1.0)$ & $0.60 .5,0.9)$ & $0.8(0.7,1.0)$ & $1.0(0.7,1.3)$ & $0.6(0.5,0.9)$ & $0.8(0.5,1.2)$ \\
\hline \multicolumn{9}{|l|}{ Post-deployment leave } \\
\hline Yes & 1 & 1 & 1 & 1 & 1 & 1 & 1 & 1 \\
\hline No & $0.9(0.8,1.1)$ & $0.9(0.7,1.2)$ & $1.2(0.9,1.4)$ & $1.2(0.9,1.7)$ & $1.2(0.9,1.4)$ & $1.2(0.9,1.5)$ & $1.0(0.8,1.3)$ & $1.1(0.8,1.6)$ \\
\hline
\end{tabular}

${ }^{\star}$ In Army only. †Adjusted for age, education, marital status, smoking status, alcohol consumption, rank, reserve status, combat arm and Service. 
Table 4 Adjusted + odds ratios for post, traumatic stress reaction by Combat Arm, stratified by Unit Status, in Gulf Army veterans

\begin{tabular}{|c|c|c|c|}
\hline Combat Arm & $\begin{array}{l}\text { Deployed with whole } \\
\text { Unit }(n=1026)\end{array}$ & $\begin{array}{l}\text { Deployed with part } \\
\text { of Unit }(n=724)\end{array}$ & $\begin{array}{l}\text { Deployed as an } \\
\text { individual } \\
\text { reinforcement } \\
(n=290)\end{array}$ \\
\hline Combat & 1 & 1 & 1 \\
\hline Combat Support & $0.9(0.5,1.8)$ & $1.1(0.4,3.1)$ & $0.1(0.0,0.7) \ddagger$ \\
\hline Combat Services Support & $0.9(0.5,1.8)$ & $1.6(0.6,4.6)$ & $0.1(0.0,1.0)^{\star}$ \\
\hline
\end{tabular}

increased likelihood of all four health outcomes but the relation disappeared after adjusting for potential confounding (table 3), except for CDC syndrome. Eighty four per cent $(n=2466)$ of Gulf veterans took postdeployment leave. Both univariate and multivariate associations between post-deployment leave and each of the four health outcomes were not significant (table 3).

The only evidence of effect modification was that Unit status weakly modified the association between Combat Arm and posttraumatic stress reaction (likelihood ratio test: $\chi^{2}$ (degrees of freedom) $\left.=9.0(4), p=0.06\right)$. Stratifying by Unit status, the adjusted association between Combat Arm compared with a non-combat Arm and post-traumatic stress reaction was greatest in those who were deployed as an individual reinforcement to a different Unit (table 4).

\section{Discussion}

Our main findings were that rank was associated with all health outcomes; privates were around $20 \%$ more likely to report ill health than non-commissioned officers and around $70 \%$ more likely to report ill health than officers. Ex-service Gulf veterans were around two times more likely to report psychological and physical ill health.

This study is population-based, used a randomly selected representative sample of the population of UK Gulf veterans. Our questionnaire used self reporting six to seven years since deployment, which may lead to a reporting bias. ${ }^{12} 13$ The outcomes we used were approximations of health status. We used a cross sectional design from which causal relations cannot be inferred reliably.

The association between rank and ill health has been observed in US Gulf veterans, ${ }^{16}$ but the explanations are not immediately clear. It is unlikely that rank is a proxy for exposures such as organophosphate pesticides, suspected chemical weapons or immunisations as most personnel, regardless of rank, could have been exposed where there was any exposure. It is more appropriate to consider rank as a proxy indicator of socioeconomic status, ${ }^{14}$ which is associated with both psychological ${ }^{15}$ and physical morbidity ${ }^{16}{ }^{17}$ in civilian populations. Rank incorporates formal qualifications, income and experience and perhaps unhealthy lifestyles, although when we adjusted for the latter the effect of rank persisted. Rank status may parallel employment grades in civil servants where low job control in lower grades is associated
KEY POINTS

- Rank seems to be the main occupational factor associated with ill health in Gulf veterans.

- Health of those who had left the Armed Forces at the time of the survey was worse than those who were still serving.

- Pre-deployment training and postdeployment leave seem not to be associated with ill health in Gulf veterans.

- As in civilian populations, certain sociodemographic and lifestyle factors such as marital status and smoking are associated with ill health in Gulf veterans.

with increased risk for coronary heart disease. ${ }^{18}$ It is possible that healthy servicemen of lower rank were less likely to participate although we did not find any significant non-response bias. ${ }^{3}$ Also potential confounding by pre-deployment health status cannot be ruled out. ${ }^{19}$

The lack of association between Combat Arm and ill health has also been reported in US Gulf veterans, ${ }^{19}$ but not in Danish peacekeepers $^{20}$ or Vietnam veterans..$^{21-23}$ One explanation is that since the Vietnam War, the nature of conflicts has changed (shorter wars, sophisticated technology and increased peacekeeping). During the Gulf conflict the ground attack lasted only four days whereas chemical and biological weapons were a real threat for a longer time and beyond the immediate geographical frontline.

Army servicemen were no more likely to have health problems compared with the Navy or Air Force, suggesting little difference in levels of exposure, if any, to combat or environmental toxins between Services. We also did not find a significant difference between reservist and ill health, unlike several US studies, ${ }^{126}$ perhaps because the proportion of British reservists was less than $2 \%$, compared with $20 \%$ in the US.

Military discharge was associated with both physical and psychological ill health. A healthy worker effect may be a partial explanation as fitness training is integral to military life whereas civilian life is more sedentary.

The most likely explanation for the lack of association between age and ill health is that our sample was young. Except for a weak protective effect of pre-military qualifications on fatigue, educational attainment was not associated with health problems, unlike previous reports in Vietnam veterans. ${ }^{22}{ }^{23}$ Perhaps recruits gain qualifications while they are serving. Gulf veterans who were divorced, separated or widowed were around twice as likely to report psychological problems than married or cohabiting veterans, similar to associations in civilian populations. ${ }^{24}$

The association between smoking and reporting both physical and psychological ill health has also been reported in US Gulf veterans ${ }^{1}$ and in civilian populations. ${ }^{25-27}$ Alcohol consumption is reputedly high in military 
personnel $^{28}$ but we did not find this in our study, probably because of a reporting bias.

Fifteen per cent of Army servicemen were deployed as an individual reinforcement and there was some evidence that this increased ill health but only in the Combat Arm. Social support is related to health in civilian workforces. ${ }^{29}$ Perhaps non-combat personnel are protected from lack of social bonds while away from their Unit because their skills require them to function independent of their unit. In contrast with our expectations, neither pre-deployment training or post-deployment leave was significantly associated with ill health.

This study suggests that rank, and perhaps being deployed as an individual reinforcement in a combat role, are associated with poor health in UK Gulf veterans. Our findings do not support the case for specific environmental exposures in the Gulf. Discharge from the military seems to be strongly associated with poor health, as was divorce and smoking. These findings need replicating and prospective studies are required to test their predictive importance.

Neither the US Department of Defense nor the UK Ministry of Defence has had any input into the design, analysis, and reporting of the study. The views expressed here are ours and not those ing of the study. The views expressed here are ours and not those of any US or UK governmental organisation. We thank Terry English, Royal British Legion, and his staff, the Gulf veterans organisations, and the veterans who gave advice and encourage-
ment and who continue to serve on our advisory board. We ment and who continue to serve on our advisory board. We thank our colleagues in other research teams at the London
School of Hygiene and Tropical Medicine and University of Manchester for their cooperation, and Margo Pellerin for providing supportive counselling to distressed veterans or thei relatives. We thank the Ministry of Defence, in particular Amanda Bale, Linda Walpole, the Gulf War Illnesses Unit Statistics staff, the Defence Analytical Services Agency and Bernie Page for their assistance. We also thank Lt Col Philip Bolton for his valuable comments on earlier drafts.

Contributors

KI contributed to study hypothesis, analysis, drafted and preparation of manuscript; NB creation of study cohorts, preparation of manuscript; $\mathrm{MH}$ statistical advice, preparation of manuscript; LH implementing study; IP Grant holder, military advice; CU study coordinator; TD and SW principal investigators, study coordinator; TD and SW principal investigators,
generated hypotheses, planned, designed and supervised study, preparation of manuscript.

Funding: US Department of Defense.

Conflicts of interest: none.

1 Fukuda K, Nisenbaum R, Stewart G, et al. Chronic multi-symptom illness affecting air force veterans of the multi-symptom illness affecting air

2 The Iowa Persian Gulf Study Group. Self-reported illnesses and health status among Gulf War veterans. A population based study. FAMA 1997;277:238-45.

3 Unwin C, Blatchley N, Coker W, et al. Health of UK servicemen who served in the Persian Gulf War. Lancet 1999;353:169-78.
4 Persian Gulf Veterans Coordinating Board. Unexplained illnesses among Desert Storm Veterans. Arch Intern Med 1995; 155:262-8.

5 Coker W, Bhatt B, Blatchley N, et al. Clinical findings for the first 1000 Gulf war veterans in the Ministry of Defence's medical assessment programme. BMF 1999;318:290-4.

6 Gray GC, Hawksworth AW, Tyler CS, et al. Gulf War Veterans' Health Registries. Who is most likely to seek evaluation? Am f Epidemiol 1998;148:343-9.

7 O'Brien L. Traumatic events and mental health. Cambridge: Cambridge University Press, 1998.

8 Chalder T, Berelowitz G, Pawlikowska T, et al. Development of a fatigue scale. F Psychosom Res 1993;37:147-53.

9 Derogatis L, Lipman R, Rickels K, et al. The Hopkins Symptom Checklist (HSCL): a self report symptom inventory. Behav Science 1974;19:1-15.

10 Goldberg D, Williams P. A user's guide to the General Health Ouestionnaire. Windsor: NFER-NELSON, 1988.

11 American Psychiatric Association. Diagnostic and statistical manual of mental disorders. Washington, DC: American Psychiatric Association, 1994.

12 McCauley L, Joos S, Lasarev M, et al. Strategies to assess validity of self-reported exposures during the Persian Gulf War. Environ Res 1999;81:195-205.

13 Gray G, Kaiser K, Hawksworth A, et al. Increased postwar symptoms and psychological morbidity among US Navy Gulf War veterans. Am f Trop Med Hyg 1999;60:758-66.

14 Seltzer C, Jablon S. Army rank and subsequent mortality by cause: 23 year follow up. Am 7 Epidemiol 1977;105:559-66.

15 Weich S, Lewis G. Poverty, unemployment, and common mental disorders: population based cohort study. BMf 1998;317:115-19.

16 Sloggett A, Joshi H. Higher mortality in deprived areas: community or personal disadvantage? BMf 1994;309: 1470-4.

17 Sloggett A, Joshi H. Deprivation indicators as predictors of life events 1981-1992 based on the UK ONS longitudinal study. F Epidemiol Community Health 1998;52:228-33.

18 Marmot M, Bosma $\mathrm{H}$, Hemingway $\mathrm{H}$, et al. Contribution of job control and other risk factors to social variations in corjob control and other risk factors to social variat

19 Dlugosz L, Hocter W, Kaiser K, et al. Risk factors for mental disorder hospitilization after the Persian Gulf War: US Armed Forces, June 1, 1991-September 30, 1993. F Clin Epidemiol 1999;52:1267-78.

20 Suadicani P, Ishoy T, Guldager B, et al. Determinants of ong-term neuropsychological symptoms. The Danish Gulf War Study. Dan Med Bull 1999;46:423-7.

21 Goldberg J, True W, Eisen S, et al. A twin study of the effects of the Vietnam war on posttraumatic stress disorder. $\mathcal{F A M A}$ 1990;263:1227-32.

22 O'Toole B, Marshall R, Schureck R, et al. Risk factors for posttraumatic stress disorder in Australian Vietnam veterans. Aust NZ 7 Psychiatry 1998;32:21-31.

23 Centers for Disease Control Vietnam Experience Study. Health status of Vietnam Veterans. I. Psychosocial characterisitics. FAMA 1988;259:2701-7.

24 Richards M, Hardy R, Wadsworth M. The effects of divorce and separation on mental health in a national UK birth cohort. Psychol Med 1997;27:1121-8.

25 Breslau N, Kilbey MM, Andreski P. Nicotine dependence and major depression. New evidence from a prospective investigation. Arch Gen Psychiatry 1993;50:31-5.

26 Glass RM. Blue mood, blackened lungs:depression and smoking. $\mathscr{F} A M A$ 1990;264:1583-4.

27 Peto R, Lopez AD, Boreham J, et al. Mortality from tobacco in developed countries: indirect estimates from national vital statistics. Lancet 1992;339:1268-78.

28 Bray R, Marsden M, Peterson M. Standardized comparisons of the use of alcohol, drugs, and cigarettes among military personnel and civilians. Am $\mathcal{F}$ Public Health 1991;81:865-9.

29 Stansfeld S, Fuhrer R, Shipley M. Types of social support as predictors of psychiatric morbidity in a cohort of British Civil Servants (Whitehall II Study). Psychol Med 1998;28: 881-92. 